\title{
Further studies on the reliability of the bacitracin inhibition test for the presumptive identification of Lancefield group A streptococci
}

\author{
D. J. COLEMAN, D. McGHiE, AND G. M. TEBBUTt
}

From the Regional Public Health Laboratory, East Birmingham Hospital, Birmingham B9 5ST

SUMMARY The reliability of the bacitracin inhibition test to differentiate between 125 Lancefield group A and 122 non-group A beta-haemolytic streptococci was studied. Bacitracin discs containing $0.02,0.04$, or 0.1 international units and the conditions recommended by both the Association of Clinical Pathologists and the Federal Drug Administration for routine sensitivity testing were used. The results suggest that the presence or absence of a zone of inhibition around a 0.04 unit disc can be used routinely for the presumptive identification of group A streptococci and that a specific zone size can be used for reading the test only with a $0 \cdot 1$ unit disc.

Infections caused by beta-haemolytic streptococci of Lancefield group A can lead to rheumatic fever or glomerulonephritis. It is therefore important to distinguish this group from other beta-haemolytic streptococci. In 1953 Maxted reported a method for differentiating streptococci belonging to group $\mathbf{A}$ from other beta-haemolytic streptococci by the sensitivity of group A strains to bacitracin. Filter paper squares were soaked in a solution of bacitracin ( 5 international units per $\mathrm{ml}$ ) and rapidly dried. The strain of streptococcus to be tested was streaked on the surface of a blood agar plate and a bacitracin impregnated filter paper square was placed on the inoculated area. After $24 \mathrm{~h}$ incubation at $37^{\circ} \mathrm{C}$ the plate was examined for zones of inhibition. When over 3000 strains were tested the method was found to identify $99.9 \%$ of group A strains. Levinson and Frank (1955), using a different medium and filter paper discs $6.4 \mathrm{~mm}$ in diameter, reported that for optimum performance the discs needed to be soaked in a bacitracin solution of only 1 unit per $\mathrm{ml}$. They concluded that the bacitracin test was suitable for differentiating streptococci from respiratory sites whenever it was not feasible to use serological methods and also for conducting large-scale epidemiological investigations on respiratory disease.

However, since that time there have been varying opinions on the usefulness of this test. It has been performed in a variety of different ways with different inocula, media, disc contents, and interpretative

Received for publication 11 October 1976 criteria and direct comparison of the results of different workers is impossible. In investigating the reliability of this test two main questions arise. First, are all the commercially available bacitracin discs suitable for routine testing? Second, what criteria should be applied in the interpretation of the test?

Bacitracin discs supplied by different manufacturers do not necessarily contain the same concentrations of bacitracin, and discs ranging from 0.02 to 0.2 international units per disc are available. Results obtained by Chitwood et al. (1969) indicate that differences in the bacitracin contents of discs can influence the reliability of the bacitracin inhibition test. Using the presence or absence of a zone of inhibition as the criterion for reading the test, they found unacceptable differences in the performance of discs obtained from four manufacturers.

Although Maxted (1953) originally used the presence or absence of a zone of inhibition to demonstrate bacitracin sensitivity, Washington et al. (1974), using a disc content of between 0.02 and 0.04 unit, successfully employed a specific zone size of $11 \mathrm{~mm}$ to differentiate group A from non-group A strains. On the other hand, Ederer et al. (1972), using discs containing 0.04 unit of bacitracin and the manufacturer's recommendations of a specific zone of inhibition of $10 \mathrm{~mm}$, found that $6 \%$ of group A strains were not identified and $13 \%$ of non-group $A$ streptococci were wrongly identified as group A, and Arvilommi (1976) falsely identified $43 \%$ of nongroup A strains as group A using 0.2 unit discs and a 
cut-off zone size of $10 \mathrm{~mm}$ recommended by the manufacturer.

This paper describes a comparison of the performance of bacitracin discs containing 0.02, 0.04, and $0 \cdot 1$ IU using the conditions recommended by both the Association of Clinical Pathologists (ACP) and the Federal Drug Administration (FDA) for routine antibiotic sensitivity testing. By using these standardised test conditions it is hoped to derive reliable interpretative criteria for the bacitracin inhibition test.

\section{Methods}

\section{STREPTOCOCCI}

A total of 247 strains of streptococci, which showed beta-haemolysis on Columbia agar (Oxoid) with $5 \%$ horse blood, were studied. Streptococcal antigen extracts were prepared by the autoclave method (Rantz and Randall, 1955) and were tested against streptococcal antisera (Wellcome Laboratories, Beckenham, Kent) by counter-current immunoelectrophoresis (Edwards and Larson, 1973).

\section{BACITRACIN}

Bacitracin powder, zinc salt, with a stated potency of 64 international units (IU) per $\mathrm{mg}$ and bacitracin discs containing $\mathbf{0} \cdot \mathbf{1}, \mathbf{0 . 0 4}$ or $\mathbf{0 . 0 2}$ IU were obtained as a special order from Scientific Hospital Services Ltd, Liverpool.

Bacitracin discs were also purchased from the following sources: Bacitracin Discs (Oxoid), Bacitracin Discs (Mast Laboratories), TaxoA (Baltimore Biological Laboratories, BBL), and Differential Discs (Difco Laboratories). All discs were stored at $4^{\circ} \mathrm{C}$ and the bacitracin powder was kept in a desiccator at $4^{\circ} \mathrm{C}$.

DETERMINATION OF MINIMUM INHIBITORY CONCENTRATION (MIC) TO BACITRACIN

The MICs were determined by the agar dilution method (Ericsson and Sherris, 1971). A stock solution of bacitracin (100 IU per $\mathrm{ml}$ ) was prepared by dissolving $100 \mathrm{mg}$ of bacitracin powder in $64 \mathrm{ml}$ of distilled water (a few drops of normal hydrochloric acid were added to effect a solution). Appropriate dilutions were prepared at 10 times the final concentration, and $2 \mathrm{ml}$ of each dilution was added to $18 \mathrm{ml}$ of molten Mueller-Hinton agar (BBL) containing $5 \%$ defibrinated horse blood at $56^{\circ} \mathrm{C}$. The final concentrations ranged from 0.008 to $1.0 \mathrm{IU}$ per $\mathrm{ml}$ (see Fig. 1). Streptococci were grown in Brain Heart Infusion Broth (Oxoid) enriched with $10 \%$ horse serum No. 5 (Wellcome) for $24 \mathrm{~h}$ at $37^{\circ} \mathrm{C}$. Each culture was agitated on a Vortex mixer for 30 s and diluted in saline to give a nephelometer reading (Unigalvo Type 200, Eel Ltd, Essex) similar 을 to that of a barium sulphate $\left(\mathrm{BaSO}_{4}\right)$ standard $\underset{\mathrm{F}}{\overrightarrow{\mathrm{f}}}$ $\left(0.05 \mathrm{ml}\right.$ of $1 \%$ (w/v) $\mathrm{BaSO}_{4}$ added to $99.5 \mathrm{ml}$ of $1 \% \mathrm{H}_{2} \mathrm{SO}_{4}$ ). Each plate was inoculated with about $0.001 \mathrm{ml}$ of the streptococcal suspensions containing $\frac{\bar{\sigma}}{\overline{\frac{5}{5}}}$ $10^{4}-10^{5}$ colony-forming units (cfu) using an inocula- $\overrightarrow{\widehat{\phi}}$ replicating apparatus (Denley Ltd, Bolney, Sussex), and the plates were incubated at $37^{\circ} \mathrm{C}$ for $18 \mathrm{~h}$.

\section{SENSITIVITY OF STREPTOCOCCI TO BACI- TRACIN}

(1) Federal Drug Administration recommendations for routine sensitivity testing (NCCLS Subcommittee ${ }_{0}$ on Antimicrobial Susceptibility Testing, 1974) of Streptococcal suspensions containing $10^{7}-10^{8} \mathrm{cfu}$ per $\mathrm{ml}$ were prepared as previously described and were $\vec{\circ}$ inoculated onto Mueller-Hinton agar containing $5 \%$ horse blood using ' $Q$ '-tips (Cheeseborough-Ponds $\vec{Z}$ Ltd, London). After a few minutes bacitracin discs (Scientific Hospital Services Ltd) were placed on the agar and allowed to prediffuse at room temperature for $15 \mathrm{~min}$ before the plates were incubated at $37^{\circ} \mathrm{C}$. for $18 \mathrm{~h}$. Inhibition zones were measured with vernier calipers.

(2) ACP recommendations for routine sensitivity? testing (Stokes and Waterworth, 1972)

Streptococci were grown in Brain Heart Infusion $\overrightarrow{\vec{F}}$ Broth with $10 \%$ horse serum at $37^{\circ} \mathrm{C}$ for $24 \mathrm{~h}$, and a $\frac{\mathrm{O}}{3}$ $5 \mathrm{~mm}$ loopful of each suspension was added to $3 \mathrm{ml}$ of quarter-strength Ringer's saline to give a concentration of about $10^{5} \mathrm{cfu}$ per ml. Diagnostic Sensitivity Test agar (Oxoid) containing $5 \%$ saponin? lysed horse blood was inoculated by flooding the plate with a streptococcal suspension. Excess fluid was removed and each plate was dried at $37^{\circ} \mathrm{C}$ for $15 \mathrm{~min}$. The bacitracin discs were applied as pre-

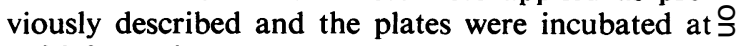
$37^{\circ} \mathrm{C}$ for $18 \mathrm{~h}$.

EFFECT OF CARBON DIOXIDE ON THE SEN-N SITIVITY OF STREPTOCOCCI TO BACITRACIN The effect of carbon dioxide on the MICs and on 0 the disc sensitivity tests of 24 strains of streptococci was studied by incubating the plates in a candle jar for $18 \mathrm{~h}$ at $37^{\circ} \mathrm{C}$.

PERFORMANCE TESTING OF BACITRACIN DISCS $\stackrel{\mathscr{\infty}}{+}$ FROM DIFFERENT SUPPLIERS

Mueller-Hinton agar containing $5 \%$ horse blood $\frac{\vec{D}}{\mathbb{D}}$ was poured on levelled glass assay plates $(30 \times \stackrel{\mathbb{Q}}{\stackrel{\oplus}{\mathscr{P}}}$ $30 \mathrm{~cm}$ ) to give an agar depth of $4 \mathrm{~mm}$, and each plate was dried at $37^{\circ} \mathrm{C}$ for $15 \mathrm{~min}$. A streptococcalo strain with an MIC of 0.01 IU bacitracin per ml was selected and grown in Brain Heart Infusiono 


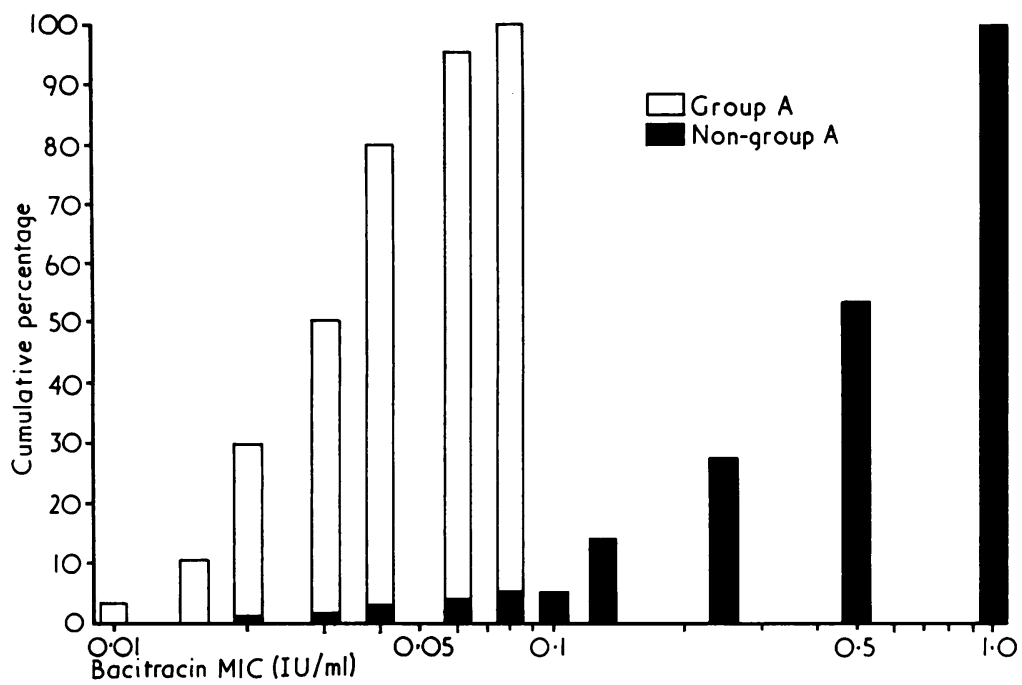

Fig. 1 Distribution of bacitracin MIC values in 125 strains of group A streptococci and in 122 strains of non-group $A$ streptococci. Non-group $A$ indicates strains belonging to groups $B, C, D$, and $G$.

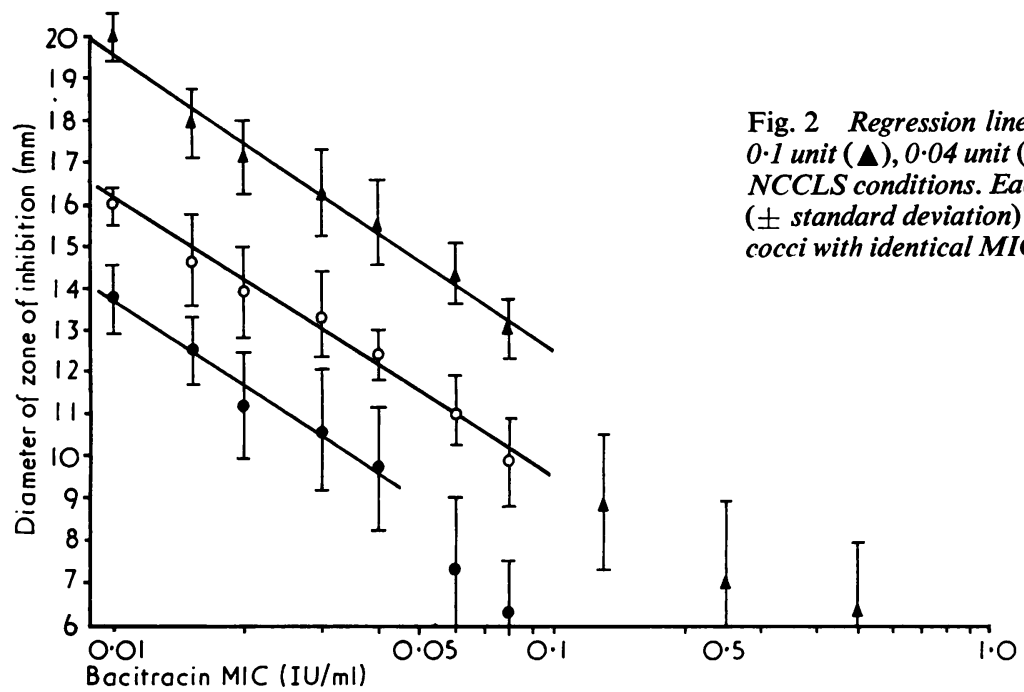

Broth containing $10 \%$ horse serum for $24 \mathrm{~h}$ at $37^{\circ} \mathrm{C}$. The turbidity was adjusted to about $10^{8} \mathrm{cfu}$ per $\mathrm{ml}$ and $20 \mathrm{ml}$ of this suspension was added to $180 \mathrm{ml}$ of Mueller-Hinton broth (BBL). Each assay plate was inoculated by flooding the agar with $25 \mathrm{ml}$ of this diluted suspension. Excess fluid was removed and the plate was dried at $37^{\circ} \mathrm{C}$ for $15 \mathrm{~min}$. Fifty bacitracin discs of each concentration from Scientific Hospital Services and 50 discs from each of the other manufacturers were mixed in a sterile jar, and 100 discs were applied to each assay plate. The plates were incubated at $37^{\circ} \mathrm{C}$ for $18 \mathrm{~h}$ and inhibition zones were measured with vernier calipers.

\section{Results}

The distribution of MICs for bacitracin of the streptococci are shown in Fig. 1. All 125 Lancefield group A strains were inhibited by a concentration of $0.08 \mathrm{IU}$ per $\mathrm{ml}$ but eight of the 122 non-group A 


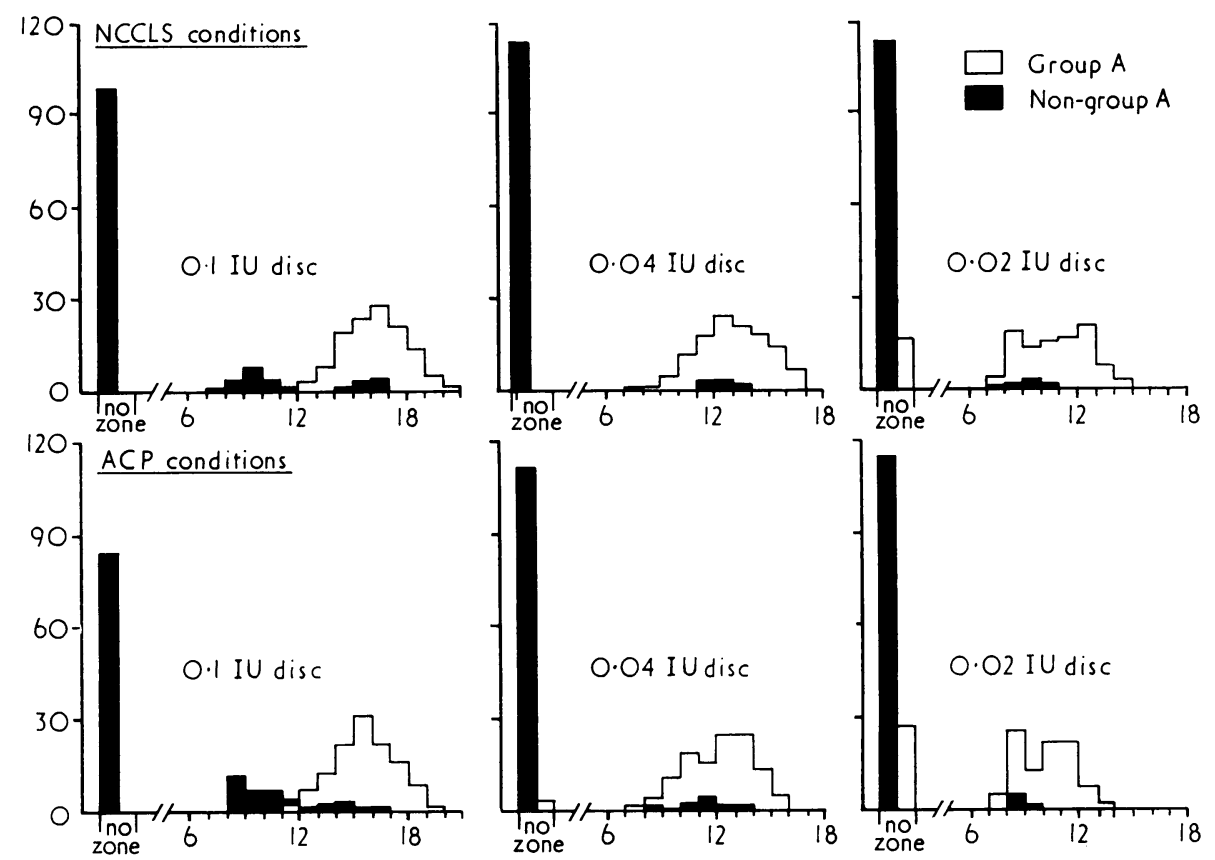

Fig. 3 Diameters of inhibition zone produced by 248 strains of streptococci against bacitracin discs of different concentrations using ACP and NCCLS conditions.

strains, one group B, two group G, and five group C strains were also inhibited by this concentration of bacitracin. Incubation in carbon dioxide did not alter the bacitracin MICs of the streptococci but it enabled easier reading of the end-points because of the heavier growth.

The regression lines were derived by plotting the mean diameter of the inhibition zones for each of the three bacitracin disc contents $(0.1,0.04$, and $0.02 \mathrm{IU}$ per $\mathrm{ml}$ ) against the corresponding MIC (Fig. 2). In general there was a straight-line relationship between the MICs and zone diameters although for the $0 \cdot 1$ unit disc this relationship did not hold for MICs greater than $0.08 \mathrm{IU}$ per ml.
The distribution of the inhibition zones for each $\overrightarrow{\vec{p}}$ content of bacitracin disc tested was similar using both the ACP and NCCLS test conditions (Fig. 3) A small proportion of non-group A strains had. zones of inhibition which were identical with those of group A strains, and several group A strains werénot inhibited by the 0.02 unit disc. Incubation in carbon dioxide did not alter the sizes of the inhibitiors zones of the 24 strains tested.

The results of assaying 50 bacitracin discs frong each manufacturer and the standard discs from Scientific Hospital Services against a very sensitive group A streptococcus (MIC 0.01 IU per ml) ar⿳亠े冖 shown in Table 1. The bacitracin discs from com?

Table 1 Comparison of bacitracin discs from different manufacturers. Assay organism is a sensitive streptococcus, (MIC 0.01 IU per $\mathrm{ml}$ ).

\begin{tabular}{|c|c|c|c|c|c|}
\hline \multicolumn{3}{|c|}{ Bacitracin discs } & \multicolumn{3}{|c|}{ Zone diameter $(\mathrm{mm})$} \\
\hline Source & Concentration $(I U)$ & Size $(\mathrm{mm})$ & Mean & Range & $\pm S D$ \\
\hline SHS & 0.02 & 6 & $16 \cdot 5$ & $15 \cdot 8-17 \cdot 0$ & $0 \cdot 6$ \\
\hline SHS & 0.04 & 6 & $18 \cdot 4$ & $17 \cdot 9-18 \cdot 9$ & 0.7 \\
\hline SHS & 0.1 & 6 & $20 \cdot 4$ & $19 \cdot 1-21 \cdot 2$ & 0.6 \\
\hline BBL & 0.04 & 6 & 16.9 & $16 \cdot 2-17.8$ & 0.5 \\
\hline Oxoid & 0.05 & 6 & $17 \cdot 2$ & $16 \cdot 0-18 \cdot 0$ & $0 \cdot 6$ \\
\hline Mast & $0 \cdot 1$ & 6 & 22.0 & $21 \cdot 0-23 \cdot 0$ & $0 \cdot 7$ \\
\hline Difco & NG & 10 & $20 \cdot 1$ & $19 \cdot 6-20 \cdot 7$ & $0 \cdot 5$ \\
\hline
\end{tabular}


Table 2 Zone or no zone interpretation of the bacitracin inhibition test

\begin{tabular}{|c|c|c|c|c|c|c|c|c|}
\hline \multicolumn{5}{|c|}{ NCCLS conditions } & \multicolumn{4}{|c|}{$A C P$ conditions } \\
\hline \multirow{2}{*}{$\begin{array}{l}\text { Disc } \\
\text { concentration }\end{array}$} & \multicolumn{2}{|c|}{ Group A strains } & \multicolumn{2}{|c|}{ Non-group A strains ${ }^{1}$} & \multicolumn{2}{|c|}{ Group A strains } & \multicolumn{2}{|c|}{ Non-group A strains ${ }^{1}$} \\
\hline & Zone & No zone & Zone & No zone & Zone & No zone & Zone & No zone \\
\hline $\begin{array}{l}0.1 \\
0.04 \\
0.02\end{array}$ & $\begin{array}{l}125 \\
125 \\
107\end{array}$ & $\begin{array}{r}0 \\
0 \\
18\end{array}$ & $\begin{array}{r}24 \\
9 \\
8\end{array}$ & $\begin{array}{r}98 \\
113 \\
114\end{array}$ & $\begin{array}{r}125 \\
122 \\
98\end{array}$ & $\begin{array}{r}0 \\
3 \\
27\end{array}$ & $\begin{array}{r}37 \\
8 \\
6\end{array}$ & $\begin{array}{r}85 \\
114 \\
116\end{array}$ \\
\hline
\end{tabular}

${ }^{1}$ Non-group $\mathbf{A}$ indicates strains belonging to groups $B, C, D$, and $G$.

Table 3 Reading of the bacitracin inhibition test using a minimum zone size of $12 \mathrm{~mm}$ inhibition.

\begin{tabular}{|c|c|c|c|c|c|c|c|c|}
\hline \multirow{3}{*}{$\begin{array}{l}\text { Bacitracin disc } \\
\text { concentration } \\
(I U)\end{array}$} & \multicolumn{4}{|c|}{ NCCLS conditions } & \multicolumn{4}{|c|}{$A C P$ conditions } \\
\hline & \multicolumn{2}{|c|}{ Group A strains } & \multicolumn{2}{|c|}{ Non-group A strains ${ }^{1}$} & \multicolumn{2}{|c|}{ Group A strains } & \multicolumn{2}{|c|}{ Non-group A strains ${ }^{1}$} \\
\hline & Sensitive & Resistant & Sensitive & Resistant & Sensitive & Resistant & Sensitive & Resistant \\
\hline $0 \cdot 1$ & 125 & 0 & 8 & 114 & 123 & 2 & 8 & 114 \\
\hline
\end{tabular}

${ }^{1}$ Non-group $A$ indicates strains belonging to groups $B, C, D$, and $G$.

mercial suppliers gave reproducible results with only a small range of zone diameters within a particular batch. There was a small variation in the mean zone diameters for discs from different sources of similar stated content although only one batch from each manufacturer was studied.

\section{Discussion}

Grouping of beta-haemolytic streptococci by precipitin techniques is time-consuming, and although other serological methods, such as slide agglutination (Rosendal, 1956) and co-agglutination with antibody-coated staphylococci (Christensen et al., 1973; Tebbutt et al., 1976), work well, some laboratories rely on the bacitracin inhibition test to differentiate group A streptococci from strains belonging to the other groups. It is well known that some streptococci of groups B, C, and G can be as sensitive to bacitracin as group $A$ strains, and we have confirmed that the MICs for bacitracin of group $\mathrm{A}$ and non-group $\mathrm{A}$ streptococci overlap (Fig. 1). The accuracy of the bacitracin inhibition test is therefore partly related to the proportion of these sensitive non-group A strains in the material examined. For instance, in south-east Asia many group $\mathrm{C}$ streptococci have zones of inhibition which are similar to those of group A (Maxted, personal communication).

Two methods can be used to interpret the results of the bacitracin inhibition tests; these are either the presence or absence of a zone of inhibition or the choice of a specific zone size as a cut-off point. We have found, using the zone or no-zone criterion, that the 0.04 unit bacitracin disc was clearly superior to the 0.1 and 0.02 discs using either NCCLS or ACP conditions, although three out of 125 group A streptococci were not identified by the ACP method (Table 2). With the $0 \cdot 1$ unit disc the NCCLS method falsely identified 24 out of 122 non-group A strains as group A, and the ACP method falsely identified 37 of these non-group A strains. Using the $\mathbf{0 . 0 2}$ unit disc, 18 out of 125 group A strains were not identified by the NCCLS method and 27 group A strains were not identified by the ACP method. A specific zone size of $12 \mathrm{~mm}$ diameter was chosen for the $0 \cdot 1$ unit disc because it reliably identified group A streptococci using either NCCLS or ACP conditions (Table 3) but the use of a $15 \mathrm{~mm}$ zone, as suggested by one manufacturer for this concentration of bacitracin, was not satisfactory. Although Washington et al. (1974), using discs containing between 0.02 and 0.04 unit of bacitracin, found that a cut-off point of $11 \mathrm{~mm}$ reliably identified group A streptococci, and one manufacturer, using a disc content of 0.04 unit of bacitracin, suggests a zone of $10 \mathrm{~mm}$ as a cut-off point, we were unable to find a specific zone size cut-off point with either the 0.02 or 0.04 content disc which reliably differentiated group $A$ from non-group A strains.

Non-group A beta-haemolytic streptococci are being increasingly recognised as human pathogens (eg, Finnegan et al., 1974; Horn et al., 1974) and, whenever possible, identification of these groups should be undertaken. However, group A strains, by virtue of their ability to cause the serious postinfective sequelae of rheumatic fever or glomerulonephritis, remain important and the bacitracin 
inhibition test is still the simplest method for their presumptive identification. The findings here show that there is little to choose between a 0.04 unit disc interpreted on a zone or no zone basis and a $0 \cdot 1$ unit disc interpreted by a cut-off point of $12 \mathrm{~mm}$. Since accurate measurement of the $12 \mathrm{~mm}$ cut-off point is required the 0.04 unit disc with a zone or no zone reading would appear to be a better choice for routine use.

We are grateful to Scientific Hospital Services Ltd, Liverpool, for the gift of bacitracin powder and standard bacitracin discs. We also thank Dr W. R. Maxted and Dr J. G. P. Hutchison for advice and encouragement and Mrs V. A. Whittaker for typing the manuscript.

\section{References}

Arvilommi, H. (1976). Grouping of beta-haemolytic streptococci by using coagglutination, precipitation or bacitracin sensitivity. Acta path. microbiol. scand., Section B, 84, 79-84.

Chitwood, L. A., Jennings, M. B., and Riley, H. D., Jr. (1969). Time, cost, and efficacy study of identifying group A streptococci with commercially available reagents. Appl. Microbiol., 18, 193-197.

Christensen, P., Kahlmeter, G., Jonsson, S., and Kronvall G. (1973). New method for the serological grouping of streptococci with specific antibodies adsorbed to protein A-containing staphylococci. Infect. Immunl., 7, 881-885.

Ederer, G. M., Herrmann, M. M., Bruce, R., Matsen, J. M., and Chapman, S. S. (1972). Rapid extraction method with Pronase B for grouping beta hemolytic streptococci. Appl. Microbiol., 23, 285-288.

Edwards, E. A. and Larson, G. L. (1973). Serological grouping of hemolytic streptococci by counter immunoelectrophoresis. Appl. Microbiol., 26, 899-903.
Ericsson, H. M. and Sherris, J. C. (1971). Antibiotic sensitivity testing: Report of an International Colla- $\overrightarrow{\bar{F}}$ borative Study. Acta. path. microbiol. scand., Section B Supplement No. 217.

Finnegan, P., Fitzgerald, M. X. M., Cumming, G., and흠 Geddes, A. M. (1974). Lancefield group C streptococcal endocarditis. Thorax, 29, 245-247.

Horn, K. A., Meyer, W. T., Wyrick, B. C., and Zimmer-@ man, R. A. (1974). Group B streptococcal neonatal infection. J. Amer. med. Ass., 230, 1165-1167.

Levinson, M. L. and Frank, P. F. (1955). Differentiationב of group A from other beta hemolytic streptococci with bacitracin. J. Bact., 69, 284-287.

Maxted, W. R. (1953). The use of bacitracin for identify-? ing group A haemolytic streptococci. J. clin. Path., 6, 224-226.

NCCLS Subcommittee on Antimicrobial Susceptibility Testing (1974). Performance standards for anti- - microbial disc susceptibility tests, as used in clinicalo laboratories. In Current Techniques for Antibiotic Sus- ceptibility Testing, pp. 138-155, edited by A. Balows.? Thomas, Springfield, Illinois.

Rantz, L. A. and Randall, E. (1955). Use of autoclaved extracts of hemolytic streptococci for serological grouping. Stanf. med. Bull., 13, 290-291.

Rosendal, K. (1956). Grouping of hemolytic streptococcio belonging to groups A, C and G. Acta. path. microbiol. scand., 39, 127-136.

Stokes, E. J. and Waterworth, P. M. (1972). Antibiotic Sensitivity Tests by Diffusion Methods. Broadsheet No.응 55 (revised). Association of Clinical Pathologists, $\varrho$ London.

Tebbutt, G. M., Coleman, D. J., and McGhie, D. (1976). 을 Grouping of beta-haemolytic streptococci with group-specific antibodies adsorbed to staphylococcalo protein A. J. clin. Path., 29, 1085-1087.

Washington, J. A., Martin, W. J., and Karlson, A. G융 (1974). In Laboratory Procedures in Clinical Micro-biology, edited by J. A. Washington II. Little Brown, Boston. 